\title{
Thiophenes as Phenyl Bio-isosteres: Application in Radiopharmaceutical Design-I. Dopamine Uptake Antagonists
}

\author{
MICHAEL R. KILBOURN* \\ Division of Nuclear Medicine, Department of Internal Medicine, University of Michigan Medical School, \\ Ann Arbor, MI 48109, U.S.A.
}

(Received 5 May 1989)

\begin{abstract}
Possible applications of thiophenes in radiopharmaceutical chemistry have been explored. Thiophene for benzene ring substitution was applied to the synthesis of thienyl- $\left[{ }^{18} \mathrm{~F}\right] \mathrm{GBR} 13119$, an analog of the potent and selective dopamine uptake inhibitor $\left[{ }^{18} \mathrm{~F}\right]$ GBR 13119 . In vivo regional brain distribution in mice shows essentially identical results for the thienyl and phenyl compounds (striatum/cerebellum ratios of $>4$ at $60 \mathrm{~min}$ ), suggesting successful substitution by the thiophene ring. The extension of this concept to the synthesis of no-carrier-added, high specific activity $\left[{ }^{18} \mathrm{~F}\right]$ fluorothiophenes was examined: $5-\left[{ }^{18} \mathrm{~F}\right]$ fluoro-22-thiophene carboxaldehyde was prepared in $10-20 \%$ yields by an unprecedented $\left[{ }^{18} \mathrm{~F}\right]$ fluoride-for-bromo substitution of 5-bromo-2-thiophenecarboxaldehyde. The possible advantages of thiophenes (lower $\log P$, altered metabolism) in radiopharmaceutical chemistry are discussed.
\end{abstract}

\section{Introduction}

In the rational design of new radiopharmaceuticals for imaging of brain processes using PET (positron emission tomography) or SPECT (single photon emission computed tomography), candidate compounds are usually first selected on the basis of affinity and selectivity for the desired biochemical process (enzyme, receptor binding site, etc.). Modifcations of the original structure are then considered, with two characteristics of primary importance: the ability of potential radiotracers to pass the bloodbrain-barrier, and exclusion of radiolabeled metabolites by the same membrane system. Radiotracers should show sufficient brain penetration to allow imaging within reasonable radiation dose limitations. Metabolites in the brain tissue, whether originating from brain metabolism or the product(s) of peripheral metabolism, may complicate quantitative mathematical modeling of the pharmacokinetics of the tracer; extensive metabolites in target tissue may negate the value of the radiotracer in vivo.

Extensive studies on the relationship between brain penetration and lipophilicity, including studies directly measuring brain uptake using a series of radiolabeled compounds (Raichle et al., 1975;

*All correspondence should be addressed to: Michael $\mathbf{R}$. Kilbourn, Ph.D., Division of Nuclear Medicine, 3480 Kresge III, University of Michigan, Ann Arbor, MI 48109, U.S.A.
Dischino et al., 1983), or correlating drug efficacy and $\log P$, have shown that there is apparently a "window" of optimum lipophilicity, centered near log $P=2$ (Hansch et al., 1968; Glave et al., 1972; Biagi et al., 1980; Hansch and Clayton, 1973; Timmermans et al., 1977). Radiotracers that fall below this window, and are highly polar, are poorly extracted by the brain unless an active transport system is available (such as with carbohydrates and amino acids). Radiotracers which are very lipophilic, and probably extensively and tightly bound to blood macromolecules, are also poorly extracted. Although there are certainly exceptions to this "optimum $\log P$ ", it is remarkable how consistent the many disparate structure-activity studies have been, and the concept of altering the $\log P$ to maximize brain penetration (or, conversely, to prevent CNS activity: Hansch et al., 1987 ) is certainly worthwhile.

It is thus often desirable to alter the lipophilicity of a radiotracer without changing the biological characteristics (affinity or specificity for intended physiological process). In some cases this has been very successful, as with the synthesis of radiolabeled butyrophenone neuroleptics: increasing the lipophilicity of spiperone by the attachment of a short alkyl or fluoroalkyl chain at the amide position gave derivatives with enhanced brain extraction and no loss of specificity or affinity for the dopamine $\mathrm{D}_{2}$ receptor, and thus improved imaging agents for PET (Welch $e t$ al., 1986). Alterations in drug structures must also 
include considerations of metabolism; however, the design of radiotracers which will not suffer peripheral metabolism is more difficult, due to the efficiency of the hepatic metabolizing enzymes at handling xenobiotics. Although drug metabolism is a major area of research in pharmacology, it is not yet possible to always predict a priori the metabolic products of a given radiotracer structure.

The alteration of drug molecules by increasing or decreasing the length of alkyl chains is not a universal solution to increasing BBB permeability. Such changes may not be possible (lack of alkyl chains in the chemical structure); may yield derivatives with diminished specificity and affinity for the target system (receptor binding site, enzyme active site); or may produce undesirable metabolites. For example, we have previously prepared the dopamine reuptake inhibitor $\left[{ }^{18} \mathrm{~F}\right]$ GBR $13119\left(1-\left[\left(4-\left[{ }^{18} \mathrm{~F}\right]\right.\right.\right.$ fluorophenyl)-(phenyl)methoxy)ethyl]-4-(3-phenylpropyl)piperazine) as a potential imaging agent for PET (Kilbourn and Haka, 1988). This molecule offers little in the way of alterations in structure: removing the ethoxy linkage yields a compound $\left(\left[{ }^{18} \mathrm{~F}\right]\right.$ fluorocinnarizine; Kilbourn, unpublished) similar to flunnarizine and cinnarizine, which are calcium channel blockers with little in vivo specificity (but possibly some affinity) for the dopamine uptake site. Altering the length of the 3-phenylpropyl moiety rapidly diminishes binding affinity (phenylpropyl, $\mathrm{IC}_{50}=$ $1.9 \mathrm{nM}$; phenethyl, $6.7 \mathrm{nM}$; benzyl, $34 \mathrm{nM}$ : Van der Zee et al., 1980).

Although a phenyl group cannot be "shortened" by one carbon, as cyclopentadiene is not equivalent to benzene, a reasonable option is the substitution of a thiophene ring. Thiophenes can be considered as bioisoteres of phenyl rings, and maintain the steric bulk, pi-electron cloud and planar structure of a phenyl ring. Thiophenes, however, are more polar (i.e. more hydrophilic) than phenyl groups (log $P$ benzene $=2.15$, thiophene $=1.81$ : Leo et al., 1971), and thus are excellent candidates for a means to lower $\log P$ values of radiopharmaceuticals which are otherwise not amenable to significant alteration in structure. Thiophenes, due to the presence of a heteroatom and a more electron-rich aromatic ring, may also be metabolized by different routes or different rates (or both), as compared to the phenyl analogs. Although thiophenes have been evaluated as a portion of numerous new drugs (Press, 1986) less is known of the routes of metabolism of these compounds.

In this work, we have examined the substitution of a thiophene ring for one phenyl ring in the structure of $\left[{ }^{18} \mathrm{~F}\right]$ GBR 13119 , a dopamine reuptake inhibitor, to produce an entirely new compound we have termed thienyl $-\left[{ }^{18} \mathrm{~F}\right]$ GBR 13119 . The effects of this substitution on the regional distribution in mouse brain have been examined. In preliminary experiments we have also investigated the synthesis of high specific activity, no carrier added ${ }^{18} \mathrm{~F}$-fluorinated thiophenes by nucleophilic aromatic substitution reactions.

\section{Experimental}

\section{Materials}

(4-Fluorophenyl)(2-thienyl)methanone was obtained from Lancaster Synthesis, Inc. 5-Bromo2-thiophene carboxaldehyde, 4-bromo-2-thiophenecarboxaldehyde, 5-nitro-2-thiophenecarboxaldehyde, $N, N, N, N$-tetraethylsulfamide, dimethylsulfoxide, lithium aluminum hydride ( $1 \mathrm{M}$ in tetrahydrofuran, LAH), thionyl chloride, and toluene were obtained from Aldrich Chem Co. 1-(2-Hydroxyethyl)-4-(3phenylpropyl)piperazine was prepared by literature methods (Van der Zee et al., 1980). Thin layer chromatography was done using plastic-backed silica gel TLC plates (Eastman) and glass-backed $C_{18}$ TLC plates (Whatman).

\section{Production of $\left[{ }^{18}\right.$ F]fluoride}

High specific activity $\left[{ }^{18} \mathrm{~F}\right]$ fluoride ion was produced by the proton irradiation of ${ }^{18} \mathrm{O}$ enriched water (95-99\%, Isotec) held in an all-silver cyclotron target (Mulholland et al., 1989).

\section{(4- ${ }^{18}$ F]Fluorophenyl)(2-thienyl)methanone (1)}

To a solution of no-carrier-added tetrabutylammonium $\left[{ }^{18} \mathrm{~F}\right]$ fluoride in $N, N, N, N$-tetraethylsulfamide $(100 \mu \mathrm{L})$ was added $2 \mathrm{mg}$ of (4-fluorophenyl)(2thienyl)methanone, and the solution heated at $155^{\circ} \mathrm{C}$ for $20 \mathrm{~min}$. An aliquot was removed and partitioned between water and diethyl ether. Incorporation of ${ }^{18} \mathrm{~F}$ into 1 ranged from 20 to $30 \%$ (corrected). TLC: silica gel, $8 / 2$ pentane/ether $R_{\mathrm{f}} 1=0.37, R_{\mathrm{f}}$ 4-fluorobenzophenone $=0.55$.

\section{(4- ${ }^{18}$ FlFluorophenyl)(2-thienyl)methanol (2)}

The crude solution of 1 in tetraethylsulfamide was treated with $200 \mu \mathrm{L}$ of $1 \mathrm{M} \mathrm{LAH} \mathrm{in} \mathrm{THF.} \mathrm{After}$ $5 \mathrm{~min}$, the reaction was quenched by slow addition of $2 \mathrm{~N}$ sulfuric acid, and the product extracted into diethyl ether. Isolated yields of benzhydrol 2 ranged from 20 to $30 \%$ (from $\left[{ }^{18} \mathrm{~F}\right]$ fluoride), and showed complete reduction of the ketone. TLC: silica gel, $8 / 2$ pentane/ether, $R_{\mathrm{f}} \mathbf{1}=0.37, \quad R_{\mathrm{f}} \quad \mathbf{2}=0.17, \quad R_{\mathrm{f}} \quad 4-$ fuorobenzhydrol $=0.18$.

\section{(4- ${ }^{18}$ F]Fluorophenyl)(2-thienyl)chloromethane (3)}

The solution of alcohol 2 in ether was evaporated to dryness ( $\mathrm{N}_{2}$ flow) and $200 \mu \mathrm{L}$ of thionyl chloride added. The solution was heated at $100^{\circ} \mathrm{C}$ (closed vessel) for $30 \mathrm{~min}$, then cooled and the thionyl chloride evaporated with a slow stream of nitrogen gas. Conversion of the alcohol to the chloride 3 was confirmed by TLC: silica gel, $8 / 2$ pentane/ether $R_{f}$ $3=0.68$.

Thienyl- $\left[{ }^{18} F\right] G B R \quad 13119 \quad\left(1-\left[\left(4-\left[{ }^{18} F\right]\right.\right.\right.$ fluorophenyl) (2-thienyl)-methoxy)ethyl]-4-(3-phenylpropyl)piperazine, 4)

To the crude residue of chloride 3 was added $20 \mathrm{mg}$ of $N$-(2-hydroxyethyl)-N-(3-phenylpropyl)- 
piperazine, one drop of toluene, and the mixture heated at $160^{\circ} \mathrm{C}$ for $25 \mathrm{~min}$. After cooling, the dark residue was dissolved in $100 \mu \mathrm{L}$ of methanol and added to $10 \mathrm{~mL}$ of water. The aqueous mixture was passed through a C-18 Sep-Pak and the solid phase washed with water. The products were then washed off with $2 \mathrm{~mL}$ of pentane, and the pentane solution passed through a silica gel Sep-Pak. The products are collected on the solid phase. The silica is washed with $40 \mathrm{~mL}$ of $50 / 50$ pentane $/ \mathrm{CH}_{2} \mathrm{Cl}_{2}$, and the product 4 eluted with $5 \mathrm{~mL}$ of $5 \%$ methanol $/ \mathrm{CH}_{2} \mathrm{Cl}_{2}$. The organic solvents were evaporated and the product formulated in $0.9 \%$ saline with a trace of hydrochloric acid. Analysis by TLC: silica, $10 \%$ methanol $/ \mathrm{CH}_{2} \mathrm{Cl}_{2}, \quad R_{\mathrm{f}} \quad \mathbf{4}=0.54 ; \quad R_{\mathrm{f}} \quad 2=0.63 ; \quad R_{\mathrm{f}}$ $3=0.76$; silica, $2.4 \%$ EtOH $/ \mathrm{CH}_{2} \mathrm{Cl}_{2}, 3 \mathrm{dev}$., $\boldsymbol{R}_{\mathrm{f}}$ $4=0.27, \quad R_{\mathrm{f}} \quad$ GBR $\quad 13119=0.41: \quad \mathrm{C}_{18}, \quad 80 / 20$ $\mathrm{EtOH} / \mathrm{H}_{2} \mathrm{O}, R_{\mathrm{f}} 4=R_{\mathrm{f}}$ GBR $13119=0.46$.

\section{Nucleophilic ${ }^{18} \mathrm{~F}$-fluorination of thiophenes}

Aromatic nucleophilic substitution reactions were conducted by methods similar to those used for phenyl compounds. $\left[{ }^{18} \mathrm{~F}\right]$ Fluoride was prepared for reaction either as a solution in DMSO containing $\mathrm{K}_{2} \mathrm{CO}_{3}(5-10 \mathrm{mg})$ and Kryptofix-2.2.2 (5-10 mg), or as $\left[{ }^{18} \mathrm{~F}\right]$ fluoride absorbed on a quaternized aminopyridine-substituted resin (Mulholland et al., 1989) and suspended in acetonitrile solution. To the $\left[{ }^{18}\right.$ F]fluoride preparations were added thiophene $(\mathbf{5}, \mathbf{6}$, or 7) and the solutions heated at $120^{\circ} \mathrm{C}$ (acetonitrile) or $150^{\circ} \mathrm{C}$ (DMSO) for $20-30 \mathrm{~min}$. Analysis of the products was by TLC (silica gel, $5 \%$ methanol/ $\mathrm{CH}_{2} \mathrm{Cl}_{2}, R_{\mathrm{f}} \mathbf{5}=0.77, R_{\mathrm{f}} 8=0.70$.

\section{Animal studies}

The regional brain distribution of thienyl$\left[{ }^{18} \mathrm{~F}\right]$ GBR 13119 in CD-1 mice was determined by methods previously described (Kilbourn, 1988). Animals (CD-1 mice, 25-30 g, Charles River) were injected via the tail vein with $1.5-3.2 \mathrm{mCi}$ of radiotracer, then killed by decapitation at $60 \mathrm{~min}$. The brains were rapidly excised and dissected into the regions of interest (striatum, cerebellum, prefrontal cortex and remainder of brain tissue). A blood sample was also obtained. All samples were counted for ${ }^{18} \mathrm{~F}$ in an automatic $\gamma$ counter, then weighed. Data were calculated as $\% \mathrm{ID} / \mathrm{g}$ for individual mice.

\section{Results and Discussion}

Modifications of radiopharmaceutical structures to maximize target organ uptake have most often involved changing the lengths of alkyl chains. In this work we have prepared a thiophene derivative of $\left[{ }^{18} \mathrm{~F}\right]$ GBR 13119 , for the first direct comparison of the in vivo regional brain distribution of a thiophene-substituted drug with the phenyl substituted drug. Thiophene rings have previously formed parts of ${ }^{18} \mathrm{~F}$ labeled radiopharmaceuticals. Thienylcyclohexylpiperidine, TCP, was labeled with ${ }^{18} \mathrm{~F}$ and examined for binding to the NMDA-receptor linked calcium channel (Kiesewetter et al., 1989). A thienyl substituted amphetamine analog was prepared for possible application as a blood flow tracer (Goodman et al., 1989). In both of these instances, however, the thiophene rings were part of the original pharmacologically active drug, and were not chosen as direct substitutions of the corresponding phenyl substituted drug, nor directly compared to the phenyl analog.

The synthesis of the thienyl analog of $\left[{ }^{18} \mathrm{~F}\right] \mathrm{GBR}$ 13119 (4, Fig 1: termed thienyl $-\left[{ }^{18}\right.$ F]GBR 13119$)$ is straightforward and follows the synthetic sequence previously developed for $\left[{ }^{18} \mathrm{~F}\right]$ GBR 13119 (Kilbourn and Haka, 1988; Haka et al., 1989). The fluoro-substituted thienylphenylketone (1) is commercially available and was used in this work. Nucleophilic exchange of ${ }^{18} \mathrm{~F}$ for ${ }^{19} \mathrm{~F}$ proceeds in expected yields of $20-30 \%$, and the intermediate ketone can be reduced in situ with lithium aluminum hydride. Conversion to the benzylic chloride is via thionyl chloride and condensation with the alcohol, to form 4, done without added base. The product 4 is then isolated by solid-phase chromatographic columns as was $\left[{ }^{18} \mathrm{~F}\right] \mathrm{GBR}$ 13119. The overall yield of thienyl$\left[{ }^{18} \mathrm{~F}\right]$ GBR $13119(3-5 \%$, EOS) is less than with the phenyl analog (10-15\% EOS) but this is directly attributable to the lower yield of the exchange reaction. By this synthetic route we have prepared modest amounts $(360 \mu \mathrm{Ci})$ of thien $y l-\left[{ }^{18} \mathrm{~F}\right] \mathrm{GBR} 13119$, with a specific activity of $1 \mathrm{Ci} / \mathrm{mmol}$; higher specific activities and higher yields should be attainable by starting the synthesis with (4-nitrophenyl)(2thienyl)methanone, which can be prepared by Friedel-Crafts acylation of thiophene with 4-nitrobenzoyl chloride (Goncalves et al., 1952). As was expected the thiophene compounds 1, 2, 3 and 4 all exhibit more polar nature on silica gel chromatography (as compared to the corresponding phenyl derivatives).

The regional brain distribution of thienyl$\left[{ }^{[8} \mathrm{F}\right] \mathrm{GBR} 13119$ at $60 \mathrm{~min}$ in $\mathrm{CD}-1$ mice shows no differences when compared to that of $\left[{ }^{18} \mathrm{~F}\right]$ GBR 13119 determined in an identical protocol (Kilbourn et al., submitted for publication). Selective uptake and accumulation in the striatum is observed, with excellent striatum/cerebellum ratios of more than 4 at $60 \mathrm{~min}$ (Table 1), which are maintained at $90 \mathrm{~min}$ (data not shown). Although the specific activity of the thienyl$\left[{ }^{18} \mathrm{~F}\right]$ GBR 13119 was quite low, the actual mass injected $(16 \mu \mathrm{g} / \mathrm{kg})$ did not apparently affect the in vivo biodistribution. Thienyl $-\left[{ }^{18} \mathrm{~F}\right] \mathrm{GBR} 13119$ is an entirely new compound, which although from our studies of regional brain uptake appears to be a dopamine uptake inhibitor, it has not been fully characterized for affinity $\left(\mathrm{IC}_{50}\right)$ or specificity (binding to other monoamine uptake systems, neurotransmitter receptors). The regional brain distribution would argue against a loss of specificity for the dopaminergic system; although it is not likely that thienyl for phenyl substitution might introduce dopamine 

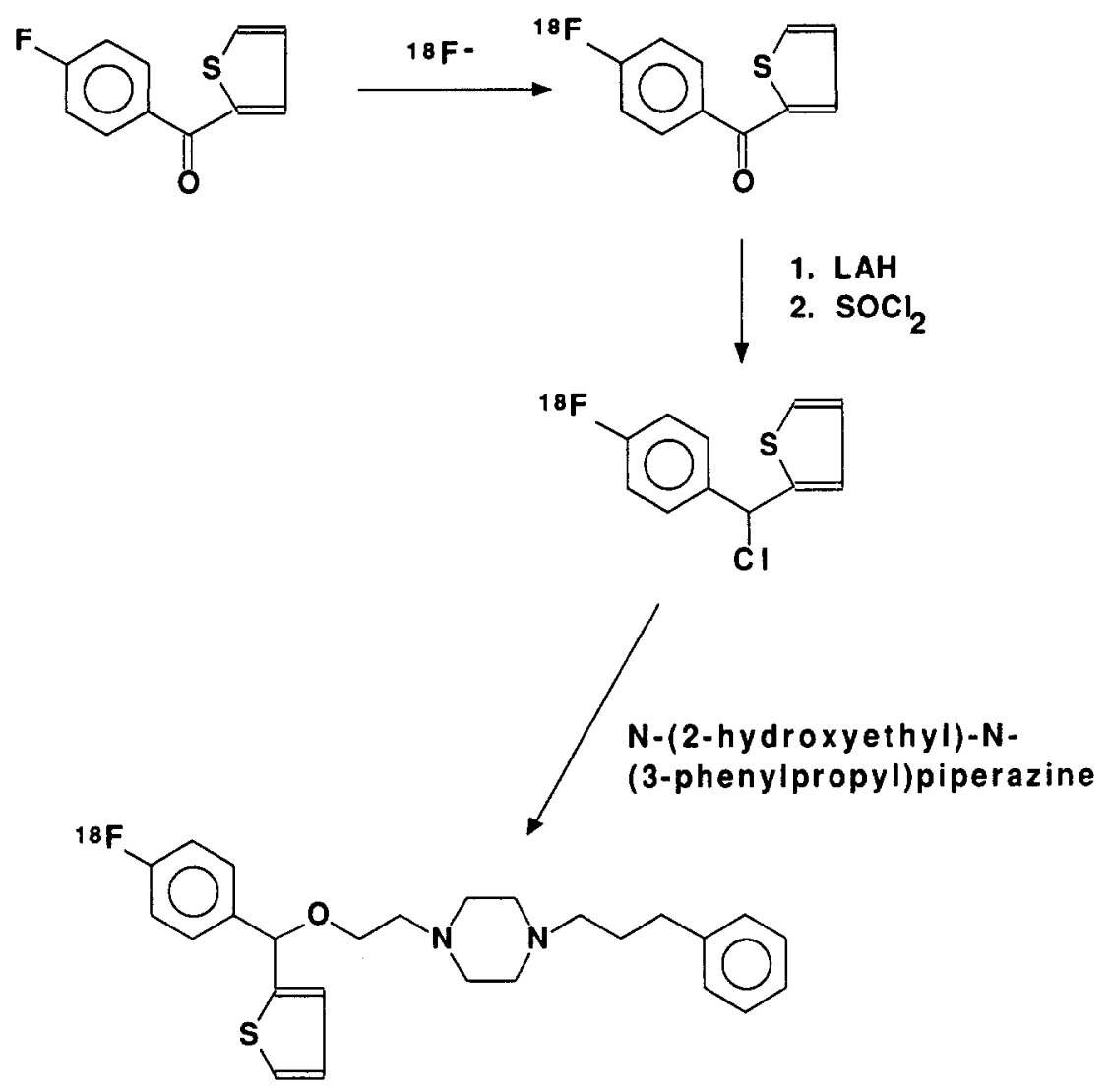

Fig. 1. Synthesis of thienyl $-\left[{ }^{18} \mathrm{~F}\right] \mathrm{GBR} 13119$.

receptor affinity, it has not been ruled out by this experimental protocol. Interestingly, a benzothiophene ( $N$-[1-(2-benzo(b)thiophenyl)cyclohexyl]piperidine, BTCP) has been recently described as a high affinity and selective inhibitor of dopamine uptake (Vignon et al., 1988).

In this synthesis of thienyl $\left[{ }^{18} \mathrm{~F}\right] \mathrm{GBR} 13119$, we have substituted a thiophene ring for an unsubstituted phenyl ring. It would also be of value to prepare ${ }^{18} \mathrm{~F}$-fluorinated thiophene rings. Although numerous fluoro-substituted thiophene rings have been reported in the literature (Reinecke and Pedaja, 1986), they have uniformly been prepared by electrophilic fluorination reactions, the best synthesis being via a thienyllithium reagent and perchloryl fluoride. Perchloryl $\left[{ }^{18} \mathrm{~F}\right]$ fluoride has been prepared (Ehrenkaufer and MacGregor, 1983) and would be suitable for such syntheses, but this would result in carrier added $\left[{ }^{18} \mathrm{~F}\right]$ fluorothiophenes. We have examined the preparation of fluorothiophenes via nucleophilic aromatic substitution with $\left[{ }^{18}\right.$ F]fluoride ion (Fig. 2). Nucleophilic substitutions of thiophene rings are well known (Rienecke and Padaja, 1986; Scrowston, 1986; Norris, 1986) but have not been described with fluoride ion as the nucleophile. No carrier added $\left[{ }^{18} \mathrm{~F}\right]$ fluoride ion was reacted with 5 bromo-2-thiophene carboxaldehyde (5) under condi- tions usually used for aromatic nucleophilic substitutions in phenyl rings. A yield of $10-20 \%$ of the $\left[{ }^{18} \mathrm{~F}\right]$ fluorothiophene (8) was obtained (TLC analysis). The identical reaction with the corresponding 4-bromo thiophene (6) did not give any fluorinated products, and reaction with the 5-nitro derivative (7) gave a low yield $(6 \%)$ of 8 but predominantly decomposition of the starting material. The yields of the $\left[{ }^{18} \mathrm{~F}\right] \mathrm{F}^{-}$for $\mathrm{Br}$ substitutions are certainly lower than that achieved for displacement of nitro groups or trimethylammonium groups attached to phenyl rings (Haka et al., 1989, and references therein), but are not unexpected for displacement of halogens. As in phenyl rings, there are ortho, meta and para relationships between thiophene ring substituents, with the

Table 1. In vivo brain distributions of $\left[{ }^{18} \mathrm{~F}\right] \mathrm{GBR} 13119$ and thienyl$\left[{ }^{18}\right.$ F]GBR 13119 in CD-1 mice, determined at $60 \mathrm{~min}$ after i.v. injection. Data given as mean $\pm \mathrm{SD}$, with $N=4$ for all data points

\begin{tabular}{lcc}
\hline & {$\left[{ }^{18} \mathrm{~F}\right] \mathrm{GBR} 13119$} & thienyl $/\left[{ }^{18} \mathrm{~F}\right] \mathrm{GBR} 13119$ \\
\hline & $\% I D / g$ & \\
Striatum & $2.8 \pm 0.11$ & $2.5 \pm 0.35$ \\
Cortex & $0.98 \pm 0.08$ & $1.06 \pm 0.21$ \\
Cerebellum & $0.66 \pm 0.06$ & $0.63 \pm 0.16$ \\
Blood & $0.89 \pm 0.16$ & $0.78 \pm 0.06$ \\
& & \\
& Ratios & \\
Striatum/cerebellum & $4.24 \pm 0.48$ & $4.14 \pm 0.96$ \\
Striatum/cortex & $2.98 \pm 0.32$ & $2.39 \pm 0.32$ \\
\hline
\end{tabular}




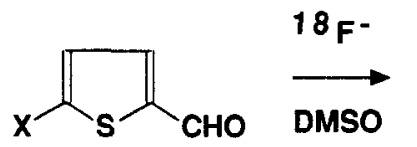

$5 \quad \mathrm{X}=\mathrm{Br}$

$\underline{6} \quad X=\mathrm{NO}_{2}$

$\mathrm{Br}$

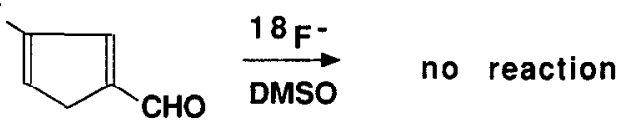

$\underline{7}$

Fig. 2. Synthesis of $\left[{ }^{18} \mathrm{~F}\right]$ fluorothiophenes via nucleophilic aromatic substitution.

2,5-substitution pattern considered the equivalent of para in benzene rings. Thus, the greater reactivity of the 5-bromo ( para) vs the 4-bromo (meta) thiophene2-carboxaldehyde is not surprising. Nitro groups on thiophenes are extremely reactive and also very activating of the ring towards numerous reactions, and the decomposition of the starting material 7 may be due to base induced condensation reactions, ring opening reactions, or stable Meisenheimer complex formation, all of which have been described with nitrothiophenes. To the best of our knowledge, this nucleophilic fluorination $\left({ }^{18} \mathrm{~F}\right.$ or $\left.{ }^{19} \mathrm{~F}\right)$ of thiophenes is unprecedented in the chemical literature. As a wide number of substituted thiophenes are known, including numerous nitro and halogen substituted thiophenecarboxaldehydes, thiophenecarbonitriles and thiophenones (Scrowston 1986), the incorporation of NCA $\left[{ }^{18}\right.$ F $]$ fluoride into a thiophene ring may form a promising new alternative in radiopharmaceutical design.

\section{Summary}

We have evaluated two possible applications of thiophenes in radiopharmaceutical chemistry, the substitution of a thiophene for a phenyl ring, and the synthesis of a high specific activity ${ }^{18} \mathrm{~F}$ labeled thiophenes. Both of these approaches appear promising as new avenues for drug modification to enhance in vivo behavior. Further studies of thiophene compounds and thiophene-substituted drugs are in progress.

Acknowledgements - This work was supported by Department of Energy Grant DE-AC02-76EV02031 and NIH Grant 2 PO1 NS15655. The author thanks the cyclotron staff for production of ${ }^{18} \mathrm{~F}$ and Phil Sherman and Teresa Pisani for the animal dissections.

\section{References}

Biagi, G. L.; Barbaro, A. M.; Guerra, M. C.; Babbini, M.; Gaiardi, M.; Bartoletti, M.; Borea, P. A. $R_{\mathrm{m}}$ values and structure-activity relationships of benzodiazepines. $J$. Med. Chem. 23:193; 1980.

Dischino, D. D.; Welch, M. J.; Kilbourn, M. R.; Raichle, M. E. Relationship between lipophilicity and brain extraction of C-11-labeled radiopharmaceuticals. J. Nucl. Med. 24:1030; 1983.

Ehrenkaufer, R. E.; MacGregor, R. R. Synthesis of $\left[{ }^{[8}\right.$ F]perchloryl fluoride and its reactions with functionalized aryl lithiums. Int. J. Appl. Radiat. Isot. 34:613; 1983.

Glave, W. R.; Hansch, C. Relationship between lipophilic character and anesthetic activity. J. Pharm. Sci. 61:589; 1972.

Goncalves, R.; Kegelman, M. R.; Brown, E. V. Preparation of thiophenanthenequinones II. Thenoylnitrobenzoic acids and nitrothiophenanthrenequinones. J. Org. Chem. 17:705; 1952.

Goodman, M. M.; Kabalka, G. W.; Marks, R.; Knapp, F. F.; Truelove, S. Synthesis and biological evaluation of radiohalogenated 5-halo-thiophene-2-isopropylamines: new agents to evaluate local cerebral blood flow. J. Labeled Compd. Radiopharm. 26:121; 1989.

Haka, M. S.; Kilbourn, M. R.; Watkins, G. L.; Toorongian, S. A. Aryltrimethylammonium trifluoromethanesulfonates as precursors to aryl $\left[{ }^{18} \mathrm{~F}\right]$ fluorides: inproved synthesis of $\left[{ }^{18} \mathrm{~F}\right]$ GBR 13119 . J. Labeled Compd. Radiopharm. 27: 823; 1989.

Hansch, C.; Clayton, J. M. Lipophilic character and biological activity of drugs II: the parabolic case. J. Pharm. Sci. $62: 1 ; 1973$.

Hansch, C.; Bjorkroth, J. P.; Leo, A. Hydrophobicity and central nervous system agents: on the principle of minimal hydrophobicity in drug design. J. Pharm. Sci. 76:663; 1987.

Hansch, C.; Steward, A. R.; Andersen, S. M.; Bentley, D. L. The parabolic dependence of drug action upon lipophilic character as revealed by a study of hypnotics. J. Med. Chem. 11:1; 1968.

Kiesewetter, D. O.; Rice, K. C.; Mattson, M. V.; Finn, R. D. Radiochemical synthesis of $\left[{ }^{18} \mathrm{~F}\right]$ fluorothienyl cyclohexylpiperidine $\left(\left[{ }^{18} \mathrm{~F}\right] \mathrm{FTCP}\right)$. J. Labeled Compd. Radiopharm. 26:332; 1989.

Kilbourn, M. R. In vivo binding of $\left[{ }^{18} \mathrm{~F}\right] \mathrm{GBR} 13119$ to the brain dopamine uptake system. Life Sci. 42:1347; 1988.

Kilbourn, M. R.; Haka, M. S. Synthesis of $\left[{ }^{18}\right.$ F]GBR 13119 , a presynaptic dopamine uptake blocker. Appl. Radiat. Isot. 39:279; 1988.

Kilbourn, M. R.; Carey, J. E.; Koeppe, R. A.; Haka, M. S.; Hutchins, G. D.; Sherman, P. S.; Kuhl, D. E. Biodistribution, dosimetry, metabolism and monkey PET studies of $\left[{ }^{18} \mathrm{~F}\right]$ GBR 13119 . Imaging the dopamine uptake system in vivo. Nucl. Med. Biol. In press, 1989 (Ms 223).

Kruse, H.; Hoffman, I.; Gerhards, H. J; Leven, M.; Schacht, U. Pharmacological and biochemical studies with three metabolites of monifensine. Psychopharm. 51:117, 1977.

Leenders, K. L.; Aquilonius, S-M.; Eckernas, S-A.; Hartvig, P.; Lundqvist, H.; Langstrom, B. Brain dopaminergic nerve terminals assessed in vivo using ( ${ }^{11} \mathrm{C}$ )nomifensine and positron emission tomography. J. Cereb. Blood Flow Metab. 7(Suppl. 1): S354; 1987.

Leo, A.; Hansch, C.; Elkins, D. Partition coefficients and their uses. Chem. Rev. 71:525; 1971.

Mulholland, G. K.; Hichwa, R. D.; Kilbourn, M. R.; Moskwa, J. A reliable pressurized water target for F-18 production at high beam currents. J. Labeled Compd. Radiopharm. 26:192; 1989.

Mulholland, G. K.; Mangner, T. J.; Jewett, D. M.; Kilbourn, M. R. Polymer-supported nucleophilic radiolabeling reactions with $\left[{ }^{18} \mathrm{~F}\right]$ fluoride and $\left[{ }^{11} \mathrm{C}\right] \mathrm{cyanide}$ ion on quaternary ammonium resins. J. Labeled Compd. Radiopharm. 26:378; 1989.

Norris, R. K. Nitrothiophenes and their reactions. In: 
Gronowitz, S., editor. Thiophene and Its Derivatives, Part II. New York: Wiley; 1986; 523.

Paot, J. A.; Woodruff, G. N.; Watling, K. J. Direct effect of a nomifensine derivative on dopamine receptors. $J$. Pharm. Pharmacol. 30:495; 1978.

Press, J. B. Pharmacologically active compounds and other thiophene derivatives. In: Gronowitz, S., editor. Thiophene and Its Derivatives, Vol. II. New York: Wiley; 1986: 354 .

Raichle, M. E.; Eichling, J. O.; Straatman, M. G.; Welch, M. J.; Larson, K. B.; Ter-Pogossian, M. M. Blood brain barrier permeability of ${ }^{11} \mathrm{C}$-labeled alcohols and ${ }^{15} \mathrm{O}$-labeled water. Am. J. Physiol. 230:543; 1975.

Reinecke, M.; Pedaja, P. Halothiophenes and their reactions. In Gronowitz, S., editor. Thiophene and Its Derivatives, Part II. New York: Wiley; 1986:159.

Riggs, R. M.; Nichols, D. E.; Foreman, M. M.; Truex, L. L.; Glock, D.; Kohli, J. D. Specific dopamine D-1 and DAl properties of 4-(mono- and dihydroxyphenyl)1,2,3,4-tetrahydroisoquinoline and its tetrahydrothieno[2,3-c]pyridine analogue. J. Med. Chem. 30:1454; 1987.
Scrowston, R. M. Formyl and acyl derivatives of thiophenes and their reactions. In: Gronowitz, S., editor. Thiophene and Its Derivatives, Part III. New York: Wiley; 1986: 309.

Timmermans, P. B. M.; Brands, A.; van Swieten, N. S. Lipophilicity and brain disposition of clonidine and structurally related imadazolidines. Arch. Pharm. 300:217; 1977.

Van der Zee, P.; Koger, H. S.; Gootjes, J.; Hespe, W. Aryl 1,4-dialk(en)ylpiperazines as selective and very potent inhibitors of dopamine uptake. Eur. J. Med. Chem. $15: 363 ; 1980$.

Vignon, J.; Pinet, V.; Cerruti, C.; Kamenka, J-M.; Chicheportiche, R. $\left[{ }^{3} \mathrm{H}\right](\mathrm{N}-[1-(2$-benzo(b)thiophenyl)cyclohexyl]piperidine $\left(\left[{ }^{3} \mathrm{H}\right] \mathrm{BTCP}\right)$ : a new phencyclidine analog selective for the dopamine uptake complex. Eur. J. Pharm. 148:427; 1988.

Welch, M. J.; Chi, D. Y.; Mathias, C. J.; Kilbourn, M. R.; Brodack, J. W.; Katzenellenbogen, J. A. Biodistribution of $\mathrm{N}$-alkyl and $\mathrm{N}$-fluoroalkyl derivatives of spiroperidol: radiopharmaceuticals for PET studies of dopamine receptors. Nucl. Med. Biol. 13:523; 1986. 